\title{
Fixed Point Results for a Class of Monotone Nonexpansive Type Mappings in Hyperbolic Spaces
}

\author{
Rameshwar Pandey, ${ }^{1}$ Rajendra Pant $\mathbb{D},{ }^{1}$ and Ahmed Al-Rawashdeh $\mathbb{D}^{2}$ \\ ${ }^{1}$ Department of Mathematics, Visvesvaraya National Institute of Technology, Nagpur 440010, India \\ ${ }^{2}$ Department of Mathematical Sciences, UAEU, P.O. Box 15551, Al-Ain, UAE \\ Correspondence should be addressed to Ahmed Al-Rawashdeh; aalrawashdeh@uaeu.ac.ae
}

Received 1 March 2018; Revised 24 April 2018; Accepted 30 May 2018; Published 2 July 2018

Academic Editor: Giuseppe Marino

Copyright (c) 2018 Rameshwar Pandey et al. This is an open access article distributed under the Creative Commons Attribution License, which permits unrestricted use, distribution, and reproduction in any medium, provided the original work is properly cited.

We consider a wider class of nonexpansive type mappings and present some fixed point results for this class of mapping in partially hyperbolic spaces. Indeed, first we obtain some existence results for this class of mappings. Next, we present some convergence results for an iteration algorithm for the same class of mappings. Some illustrative nontrivial examples have also been discussed. Finally, we provide an application of our results to nonlinear integral equations.

\section{Introduction}

A mapping $p$ from the set of reals $\mathbb{R}$ to a metric space $(X, \rho)$ is said to be metric embedding if $\rho(p(m), p(n))=|m-n|$ for all $m, n \in \mathbb{R}$. The image of $\mathbb{R}$ under a metric embedding is called a metric line. The image of a real interval $[a, b]=\{t \in$ $\mathbb{R}: a \leq t \leq b\}$ under metric embedding is called a metric segment. Assume that $(X, \rho)$ has a family $\mathscr{F}$ of metric lines such that, for each pair $u, v \in X(u \neq v)$, there is a unique metric line in $\mathscr{F}$ which passes through $u$ and $v$. This metric line determines a unique metric segment joining $u$ and $v$. This segment is denoted by $[u, v]$ and this is an isometric image of the real interval $[0, \rho(u, v)]$. We denote by $\gamma u \oplus(1-\gamma) v$ the unique point $w$ of $[u, v]$ which satisfies

$$
\begin{aligned}
& \rho(u, w)=(1-\gamma) \rho(u, v) \text { and } \\
& \rho(w, v)=\gamma \rho(u, v),
\end{aligned}
$$

where $\gamma \in[0,1]$. Such a metric space with a family of metric segments is called a convex metric space [1]. Moreover, if we have

$$
\begin{gathered}
\rho(\gamma u \oplus(1-\gamma) v, \gamma w \oplus(1-\gamma) z) \\
\leq \gamma \rho(u, w)+(1-\gamma) \rho(\nu, z)
\end{gathered}
$$

for all $u, v, w, z \in X$, then $X$ is said to be a hyperbolic metric space [2].

Hyperbolic spaces are more general than normed spaces and CAT(0) spaces. These spaces are nonlinear. Indeed, all normed linear and CAT(0) spaces are hyperbolic spaces (cf. [3-5]). As nonlinear examples, one can consider the Hadamard manifolds [6] and the Hilbert open unit ball equipped with the hyperbolic metric [7].

A mapping $T: X \rightarrow X$ is said to be nonexpansive if $\rho(T(u), T(v)) \leq \rho(u, v)$, for all $u, v \in X$. The study of existence of fixed point of nonexpansive mappings has been of great interest in nonlinear analysis. Fixed point theory of nonexpansive mappings in hyperbolic spaces has been extensively studied (cf. [2, 8-14]). Bin Dehaish and Khamsi [8] obtained a fixed point theorem for a monotone nonexpansive mapping in the setting partially ordered hyperbolic metric spaces.

On the other hand, a number of extensions and generalizations of nonexpansive mapping has been considered by many authors (cf. [15-26]). Greguš [21] considered the following class of nonexpansive type mappings. Let $T: X \rightarrow$ $X$ be a mapping such that, for all $u, v \in X$,

$$
\begin{aligned}
\rho(T(u), T(v)) \leq & a \rho(u, v)+b \rho(T(u), u) \\
& +c \rho(T(v), v)
\end{aligned}
$$


where $a, b$, and $c$ are nonnegative constants such that $a+$ $b+c=1$. A mapping satisfying (3) is also known as Reich type nonexpansive mapping. A mapping satisfying (3) also satisfies the following condition:

$$
\begin{gathered}
\rho(T(u), T(v)) \leq k \rho(T(u), u)+k \rho(T(v), v) \\
+(1-2 k) \rho(u, v)
\end{gathered}
$$

where $k \in[0,1)$.

Suzuki [26] introduced the following class of nonexpansive type mappings.

Definition 1 (see [26]). Let $Y$ be a nonempty subset of a Banach space $X$. A mapping $T: Y \rightarrow Y$ is said to satisfy condition $(C)$ if, for all $u, v \in Y$,

$$
\frac{1}{2}\|u-T(u)\| \leq\|u-v\|
$$

$$
\text { implies }\|T(u)-T(v)\| \leq\|u-v\| \text {. }
$$

Notice that the class of mappings satisfying (3)-(5) properly contains the class of nonexpansive mappings and need not be continuous.

Motivated by the above fact and works of Greguš [21], Suzuki [26], and others, in this paper, we make an attempt to define a wider class of nonexpansive type mapping which properly contains nonexpansive, Reich type nonexpansive, and Suzuki type nonexpansive mappings. In particular, in Section 3, we study some existence results in partially ordered hyperbolic space for this class of nonexpansive type mapping and some illustrative nontrivial examples have also been discussed. In Section 4, we present some convergence results for an iteration algorithm due to Abbas and Nazir [27]. In Section 5, we discuss an application of our results to nonlinear integral equations.

\section{Preliminaries}

Let us recall the following definition which is due to Kohlenbach [11].

Definition 2 (see [11]). A triplet $(X, \rho, H)$ is said to be a hyperbolic metric space if $(X, \rho)$ is a metric space and $H$ : $X \times X \times[0,1] \rightarrow X$ is a function such that, for all $u, v, w, z \in X$ and $\beta, \gamma \in[0,1]$, the following hold:

$$
\begin{aligned}
& \text { (K1) } \rho(z, H(u, v, \beta)) \leq(1-\beta) \rho(z, u)+\beta \rho(z, v) ; \\
& \text { (K2) } \rho(H(u, v, \beta), H(u, v, \gamma))=|\beta-\gamma| \rho(u, v) ; \\
& \text { (K3) } H(u, v, \beta)=H(v, u, 1-\beta) ; \\
& \text { (K4) } \rho(H(u, z, \beta), H(v, w, \beta)) \leq(1-\beta) \rho(u, v)+\beta \rho(z, w) .
\end{aligned}
$$

The set $\operatorname{seg}[u, v]:=\{H(u, v, \beta) ; \beta \in[0,1]\}$ is called the metric segment with endpoints $u$ and $v$. Now onwards, we write $H(u, v, \beta)=(1-\beta) u \oplus \beta v$. A subset $Y$ of $X$ is said to be convex if $(1-\beta) u \oplus \beta v \in Y$ for all $u, v \in Y$ and $\beta \in[0,1]$. When there is no ambiguity, we write $(X, \rho)$ for $(X, \rho, H)$.

Let $E$ be a partially ordered set with a partial order ' $\preceq$ ' and let $(E, \rho, \preceq)$ be a partially ordered hyperbolic metric space. We say that $u, v \in E$ are comparable whenever $u \preceq v$ or $v \preceq u$. Throughout, we will assume that order intervals are closed convex subsets of hyperbolic metric space $E$. We denote these intervals as follows:

$$
\begin{aligned}
& {[a, \longrightarrow):=\{u \in E ; a \preceq u\} \text { and }} \\
& (\longleftarrow, b]:=\{u \in E ; u \preceq b\},
\end{aligned}
$$

for any $a, b \in E$ (cf. [8]).

Definition 3 (see $[28,29])$. Let $(E, \rho)$ be a hyperbolic metric space. For any $a \in E, r>0$ and $\epsilon>0$. Set

$$
\begin{aligned}
& \delta(r, \epsilon)=\inf \left\{1-\frac{1}{2} \rho\left(\frac{1}{2} u \oplus \frac{1}{2} v, a\right) ; \rho(u, a)\right. \\
& \leq r, \rho(v, a) \leq r, \rho(u, v) \geq r \epsilon\} .
\end{aligned}
$$

We say that $E$ is uniformly convex if $\delta(r, \epsilon)>0$, for any $r>0$ and $\epsilon>0$.

Definition 4 (see [30]). A hyperbolic metric space $(E, \rho)$ is said to satisfy property $(R)$ if, for each decreasing sequence $\left\{F_{n}\right\}$ of nonempty bounded closed convex subsets of $E$, $\bigcap_{n=1}^{\infty} F_{n} \neq \emptyset$.

Uniformly convex hyperbolic spaces satisfy the property $(R)$; see [8].

Definition 5 (see $[8])$. Let $(E, \rho, \preceq)$ be a metric space endowed with a partial order. A mapping $T: X \rightarrow X$ is said to be monotone

$$
T(u) \preceq T(v) \quad \text { whenever } u \preceq v \text {, }
$$

for all $u, v \in E$.

Definition 6 (see $[8])$. Let $(E, \rho, \preceq)$ be a metric space endowed with a partial order. A mapping $T: X \rightarrow X$ is said to be monotone nonexpansive if $T$ is monotone and

$$
\rho(T(u), T(v)) \leq \rho(u, v),
$$

for all $u, v \in E$ such that $u, v$ are comparable.

Definition 7 (see [31]). Let $K$ be a subset of a metric space $(E, \rho)$. A mapping $T: K \rightarrow K$ is said to satisfy condition ( $I$ ) if there exists a nondecreasing function $g:[0, \infty) \rightarrow[0, \infty)$ satisfying $g(0)=0$ and $g(r)>0$ for all $r \in(0, \infty)$ such that $\rho(u, T(u)) \geq g(\operatorname{dist}(u, F(T)))$ for all $u \in K$, and here $\operatorname{dist}(u, F(T))$ denotes the distance of $u$ from $F(T)$.

Let $K$ be a nonempty subset of a hyperbolic metric space $(E, \rho)$ and $\left\{u_{n}\right\}$ a bounded sequence in $E$. For each $u \in E$, define

(i) asymptotic radius of $\left\{u_{n}\right\}$ at $u$ as $r\left(\left\{u_{n}\right\}, u\right)$ := $\limsup _{n \rightarrow \infty} \rho\left(u_{n}, u\right)$; 
(ii) asymptotic radius of $\left\{u_{n}\right\}$ relative to $K$ as

$$
r\left(\left\{u_{n}\right\}, K\right):=\inf \left\{r\left(\left\{u_{n}\right\}, u\right) ; u \in K\right\}
$$

(iii) asymptotic centre of $\left\{u_{n}\right\}$ relative to $K$ by

$$
A\left(\left\{u_{n}\right\}, K\right):=\left\{u \in K ; r\left(\left\{u_{n}\right\}, u\right)=r\left(\left\{u_{n}\right\}, K\right)\right\}
$$

Lim in [32] introduced the concept of $\Delta$-convergence in a metric space. Kirk and Panyanak in [33] used Lim's concept in CAT(0) spaces and showed that many Banach space results involving weak convergence have precise analogs in this setting.

Definition 8 (see [33]). A bounded sequence $\left\{u_{n}\right\}$ in $E$ is said to $\Delta$-converge to a point $u \in E$, if $u$ is the unique asymptotic centre of every subsequence $\left\{u_{n_{k}}\right\}$ of $\left\{u_{n}\right\}$.

Definition 9 (see [8]). Let $K$ be a nonempty subset of a hyperbolic metric space $(E, \rho)$. A function $\tau: K \rightarrow[0, \infty)$ is said to be a type function, if there exists a bounded sequence $\left\{u_{n}\right\}$ in $E$ such that

$$
\tau(u)=\limsup _{n \rightarrow \infty} \rho\left(u_{n}, u\right)
$$

for any $u \in K$.

We know that every bounded sequence generates a unique type function.

Lemma 10 (see [8]). Let $(E, \rho, \preceq)$ be a uniformly convex hyperbolic metric space and $K$ a nonempty closed convex subset of $E$. Let $\tau: K \rightarrow[0, \infty)$ be a type function. Then $\tau$ is continuous. Moreover, there exists a unique minimum point $z \in K$ such that $\tau(z)=\inf \{\tau(u) ; u \in K\}$.

Now, we rephrase the concept of $\Delta$-convergence in hyperbolic metric spaces.

Definition 11. A bounded sequence $\left\{u_{n}\right\}$ in $E$ is said to $\Delta$ converge to a point $z \in E$ if $z$ is unique and the type function generated by every subsequence $\left\{u_{n_{k}}\right\}$ of $\left\{u_{n}\right\}$ attains its infimum at $z$.

Abbas and Nazir [27] introduced an iteration process which can be defined in the framework of hyperbolic metric spaces as follows:

$$
\begin{aligned}
u_{1} & \in K \\
u_{n+1} & =\left(1-\alpha_{n}\right) T\left(v_{n}\right) \oplus \alpha_{n} T\left(w_{n}\right) \\
v_{n} & =\left(1-\beta_{n}\right) T\left(u_{n}\right) \oplus \beta_{n} T\left(w_{n}\right) \\
w_{n} & =\left(1-\gamma_{n}\right) u_{n} \oplus \gamma_{n} T\left(u_{n}\right) ; \quad n \in \mathbb{N},
\end{aligned}
$$

where $\left\{\alpha_{n}\right\},\left\{\beta_{n}\right\}$, and $\left\{\gamma_{n}\right\}$ are real sequences in $(0,1)$.

\section{Existence Results}

In this section, we define a new class of nonexpansive type mappings and present some auxiliary and an existence result (see Theorem 16 below). We also discuss a couple of illustrative examples.

Definition 12. Let $(E, \rho, \preceq)$ be a partially ordered metric space and let $T: E \rightarrow E$ be a monotone mapping. Then $T$ is called monotone Reich-Suzuki type nonexpansive mapping, if there exists a $k \in[0,1)$ such that

$$
\frac{1}{2} \rho(u, T(u)) \leq \rho(u, v) \quad \text { implies } \rho(T(u), T(v)) \leq k \rho(T(u), u)+k \rho(T(v), v)+(1-2 k) \rho(u, v)
$$

for all $u, v \in E$ such that $u$ and $v$ are comparable.

Lemma 13. Let $(E, \rho, \preceq)$ be a uniformly convex partially ordered hyperbolic metric space and $K$ a nonempty closed convex subset of E. Let $T: K \rightarrow K$ be a monotone mapping. Let $u_{1} \in K$ be such that $u_{1} \preceq T\left(u_{1}\right)\left(T\left(u_{1}\right) \preceq u_{1}\right)$. Then, for sequence $\left\{u_{n}\right\}$ defined by (13), we have

(a) $u_{n} \preceq T\left(u_{n}\right) \preceq u_{n+1}\left(\right.$ or $\left.u_{n+1} \preceq T\left(u_{n}\right) \preceq u_{n}\right)$;

(b) $u_{n} \preceq p$ (or $p \preceq u_{n}$ ), provided $\left\{u_{n}\right\} \Delta$-converges to a point $p \in K$, for all $n \in \mathbb{N}$.

Proof. We shall use induction to prove (a). By assumption, we have $u_{1} \preceq T\left(u_{1}\right)$. By the convexity of order interval $\left[u_{1}, T\left(u_{1}\right)\right]$ and (13), we have

$$
u_{1} \preceq w_{1} \preceq T\left(u_{1}\right)
$$

As $T$ is monotone, $T\left(u_{1}\right) \preceq T\left(w_{1}\right)$. Again, by convexity of order interval $\left[T\left(u_{1}\right), T\left(w_{1}\right)\right]$ and (13), we have

$$
T\left(u_{1}\right) \preceq v_{1} \preceq T\left(w_{1}\right) .
$$

Combining (15) and (16), we get

$$
u_{1} \preceq w_{1} \preceq T\left(u_{1}\right) \preceq v_{1} .
$$

As $T$ is monotone, $T\left(w_{1}\right) \preceq T\left(v_{1}\right)$. Again, by convexity of order interval $\left[T\left(w_{1}\right), T\left(v_{1}\right)\right]$ and (13), we have

$$
T\left(w_{1}\right) \preceq u_{2} \preceq T\left(v_{1}\right) .
$$

By (15), (16), and (18), we get

$$
u_{1} \preceq T\left(u_{1}\right) \preceq T\left(w_{1}\right) \preceq u_{2} \preceq T\left(v_{1}\right) .
$$


Thus (a) is true for $n=1$. Now, suppose it is true for $n$; that is,

$$
u_{n} \preceq \mathrm{T}\left(u_{n}\right) \preceq u_{n+1} .
$$

By convexity of order interval $\left[u_{n}, T\left(u_{n}\right)\right]$ and (13), we have

$$
u_{n} \preceq w_{n} \preceq T\left(u_{n}\right)
$$

As $T$ is monotone, $T\left(u_{n}\right) \preceq T\left(w_{n}\right)$. Again, by convexity of order interval $\left[T\left(u_{n}\right), T\left(w_{n}\right)\right]$ and (13), we have

$$
T\left(u_{n}\right) \preceq v_{n} \preceq T\left(w_{n}\right) .
$$

From (21) and (22), we have

$$
w_{n} \preceq T\left(u_{n}\right) \preceq v_{n} \preceq T\left(w_{n}\right),
$$

so $T\left(w_{n}\right) \preceq T\left(v_{n}\right)$. By convexity of order interval $\left[T\left(w_{n}\right), T\left(v_{n}\right)\right],(23)$, and (13), we have

$$
T\left(u_{n}\right) \preceq T\left(w_{n}\right) \preceq u_{n+1} \preceq T\left(v_{n}\right) .
$$

From (21), (23), and (24), we have

$$
u_{n} \preceq T\left(u_{n}\right) \preceq v_{n} \preceq T\left(w_{n}\right) \preceq u_{n+1} \preceq T\left(v_{n}\right),
$$

and then $T\left(v_{n}\right) \preceq T\left(u_{n+1}\right)$. From (25), we have

$$
u_{n+1} \preceq T\left(u_{n+1}\right) \text {. }
$$

By convexity of order interval $\left[u_{n+1}, T\left(u_{n+1}\right)\right]$ and (13), we have

$$
u_{n+1} \preceq w_{n+1} \preceq T\left(u_{n+1}\right),
$$

so $T\left(u_{n+1}\right) \preceq T\left(w_{n+1}\right)$. By convexity of order interval $\left[T\left(u_{n+1}\right), T\left(w_{n+1}\right)\right]$ and (13), we have

$$
u_{n+1} \preceq T\left(u_{n+1}\right) \preceq v_{n+1} \preceq T\left(w_{n+1}\right) .
$$

By (27) and (28), $w_{n+1} \preceq v_{n+1}$. By convexity of order interval we get $\left[T\left(w_{n+1}\right), T\left(v_{n+1}\right)\right]$. Hence, from (13), we have

$$
T\left(w_{n+1}\right) \preceq u_{n+2} \preceq T\left(v_{n+1}\right) .
$$

From (28) and (29), we have

$$
u_{n+1} \preceq T\left(u_{n+1}\right) \preceq T\left(w_{n+1}\right) \preceq u_{n+2} \preceq T\left(v_{n+1}\right) ;
$$

that is

$$
u_{n+1} \preceq T\left(u_{n+1}\right) \preceq u_{n+2} .
$$

Suppose $p$ is a $\Delta$-limit of $\left\{u_{n}\right\}$. Here the sequence $\left\{u_{n}\right\}$ is monotone increasing and the order interval $\left[u_{m}, \rightarrow\right)$ is closed and convex. We claim that $p \in\left[u_{m}, \rightarrow\right)$ for a fixed $m \in$ $\mathbb{N}$. If $p \notin\left[u_{m}, \rightarrow\right)$, then the type function generated by subsequence $\left\{u_{r}\right\}$ of $\left\{u_{n}\right\}$ defined by leaving first $m-1$ terms of the sequence $\left\{u_{n}\right\}$ will not attain an infimum at $p$, which is a contradiction to the assumption that $p$ is a $\Delta$-limit of the sequence $\left\{u_{n}\right\}$. This completes the proof.
Lemma 14. Let $(E, \rho, \preceq)$ be a partially ordered hyperbolic metric space and $K$ a nonempty subset of $E$. Let $T: K \rightarrow K$ be a monotone Reich-Suzuki type nonexpansive mapping. Then, for each $u, v \in K$,

(i) $\rho\left(T(u), T^{2}(u)\right) \leq \rho(u, T(u))$;

(ii) Either $(1 / 2) \rho(u, T(u)) \leq \rho(u, v)$ or $(1 / 2) \rho(T(u)$, $\left.T^{2}(u)\right) \leq \rho(T(u), v) ;$

(iii) Either $\rho(T(u), T(v)) \leq k \rho(T(u), u)+k \rho(v, T(v))+$ $(1-2 k) \rho(u, v)$ or $\rho\left(T^{2}(u), T(v)\right) \leq k \rho\left(T^{2}(u), T(u)\right)+$ $k \rho(T(v), v)+(1-2 k) \rho(T(u), v)$,

where $u$ and $v$ are comparable.

Proof. As $(1 / 2) \rho(u, T(u)) \leq \rho(u, T(u))$ by definition of monotone Reich-Suzuki type nonexpansive mapping, we have

$$
\begin{aligned}
\rho\left(T(u), T^{2}(u)\right) \leq & k \rho(T(u), u)+k \rho\left(T(u), T^{2}(u)\right) \\
& +(1-2 k) \rho(u, T(u)),
\end{aligned}
$$

since $1-k>0$, so

$$
\rho\left(T(u), T^{2}(u)\right) \leq \rho(u, T(u)) .
$$

To prove (ii), arguing by contradiction, we suppose that

$$
\begin{aligned}
\frac{1}{2} \rho(u, T(u)) & >\rho(u, v) \text { and } \\
\frac{1}{2} \rho\left(T(u), T^{2}(u)\right) & >\rho(T(u), v) .
\end{aligned}
$$

By (i) and triangle inequality, we have

$$
\begin{aligned}
\rho(u, T(u)) & \leq \rho(u, v)+\rho(T(u), v) \\
& <\frac{1}{2} \rho(u, T(u))+\frac{1}{2} \rho\left(T(u), T^{2}(u)\right) \\
& \leq \rho(u, T(u)),
\end{aligned}
$$
lemma.

which is a contradiction. Hence (ii) holds. Condition (iii) follows directly from condition (ii).

The following lemma is a consequence of the above

Lemma 15. Let $(E, \rho, \preceq)$ be a partially ordered hyperbolic metric space and $K$ a nonempty subset of E. Let $T: K \rightarrow K$ be a monotone Reich-Suzuki type nonexpansive mapping. Then, for all $u, v \in K$ such that $u$ and $v$ are comparable, we have

$$
\rho(u, T(v)) \leq \frac{(3+k)}{(1-k)} \rho(u, T(u))+\rho(u, v) .
$$

Theorem 16. Let $(E, \rho, \preceq)$ be a uniformly convex partially ordered hyperbolic metric space and $K$ a nonempty closed convex subset of E. Let $T: K \rightarrow K$ be a monotone Reich-Suzuki type nonexpansive mapping. Assume that there exists $u_{1} \in K$ such that $u_{1}$ and $T\left(u_{1}\right)$ are comparable. Let the sequence $\left\{u_{n}\right\}$ defined by (13) be bounded, and there exists a point $w \in K$ such that every point of the sequence $\left\{u_{n}\right\}$ is comparable with $w$ and $\liminf _{n \rightarrow \infty} \rho\left(T\left(u_{n}\right), u_{n}\right)=0$. Then $T$ has a fixed point. 
Proof. Suppose $\left\{u_{n}\right\}$ is a bounded sequence and

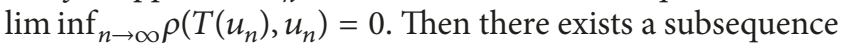
$\left\{u_{n_{j}}\right\}$ of $\left\{u_{n}\right\}$ such that

$$
\lim _{j \rightarrow \infty} \rho\left(T\left(u_{n_{j}}\right), u_{n_{j}}\right)=0
$$

By Lemma 13, we have $u_{1} \preceq u_{n_{j}} \preceq u_{n_{j+1}}$. Define $K_{j}=\{s \in K$ : $\left.u_{n_{j}} \preceq s\right\}$ for all $j \in \mathbb{N}$. Clearly, for each $j \in \mathbb{N}, K_{j}$ is closed convex and $w \in K_{j}$ so $K_{j}$ is nonempty. Set

$$
K_{\infty}=\bigcap_{j=1}^{\infty} K_{j} \neq \emptyset .
$$

Then, $K_{\infty}$ is closed convex subset of $K$. Let $u \in K_{\infty}$; then $u_{n_{j}} \preceq u$ for all $j \in \mathbb{N}$. Since $T$ is monotone, for all $j \in \mathbb{N}$,

$$
u_{n_{j}} \preceq T\left(u_{n_{j}}\right) \preceq T(u) .
$$

This implies that $T\left(K_{\infty}\right) \subseteq K_{\infty}$. Let $\tau: K_{\infty} \rightarrow[0, \infty)$ be a type function generated by $\left\{u_{n_{j}}\right\}$; that is,

$$
\tau(u)=\limsup _{j \rightarrow \infty} \rho\left(u_{n_{j}}, u\right) .
$$

From Lemma 10, there exists a unique element $z \in K_{\infty}$ such that

$$
\tau(z)=\inf \left\{\sigma(u) ; u \in K_{\infty}\right\} .
$$

By definition of type function,

$$
\tau(T(z))=\limsup _{j \rightarrow \infty} \rho\left(u_{n_{j}}, T(z)\right) .
$$

Using Lemma 15, we get

$$
\begin{aligned}
\tau(T(z))= & \limsup _{j \rightarrow \infty} \rho\left(u_{n_{j}}, T(z)\right) \\
\leq & \frac{(3+k)}{(1-k)} \limsup _{j \rightarrow \infty} \rho\left(u_{n_{j}}, T\left(u_{n_{j}}\right)\right) \\
& +\limsup _{j \rightarrow \infty} \rho\left(u_{n_{j}}, z\right)=\tau(z) .
\end{aligned}
$$

By the uniqueness of minimum point this implies that $T(z)=$ $z$, and hence the proof is completed.

Now, let us illustrate the following examples.

Example 17. Let $E=\mathbb{R}$ (the set of reals) be equipped with the usual ordering and standard norm $\|u\|=|u|$. Let $K=[0,1] \subset$ $\mathbb{R}$ and $T: K \rightarrow K$ be a mapping defined by

$$
T(u)= \begin{cases}1-\frac{u}{2}, & \text { if } u \in\left[0, \frac{1}{4}\right) \\ \frac{u}{4}+\frac{1}{2}, & \text { if } u \in\left[\frac{1}{4}, 1\right] .\end{cases}
$$

Then
(1) $T$ is not a nonexpansive mapping,

(2) $T$ is monotone Reich-Suzuki type nonexpansive mapping.

For $u=0$ and $v=1 / 4$, we have $\|T(u)-T(v)\|=7 / 16>1 / 4=$ $\|u-v\|$. Therefore $T$ is not a nonexpansive mapping.

Now, we show that $T$ is monotone Reich-Suzuki type nonexpansive mapping with $k=1 / 2$. We consider the following three cases:

(i) Let $u, v \in[0,1 / 4)$, and we have

$$
\begin{aligned}
\frac{1}{2}( & \|T(u)-u\|+\|T(v)-v\|) \\
& =\frac{1}{2}\left(\left|\frac{3 u}{2}-1\right|+\left|\frac{3 v}{2}-1\right|\right) \\
& \geq \frac{1}{2}\left|\left(\frac{3 u}{2}-1\right)-\left(\frac{3 v}{2}-1\right)\right|=\frac{3}{4}|u-v| \\
& \geq \frac{1}{2}|u-v|=\|T(u)-T(v)\| .
\end{aligned}
$$

(ii) Let $u, v \in[1 / 4,1]$, and we have

$$
\begin{aligned}
\frac{1}{2}( & \|T(u)-u\|+\|T(v)-v\|) \\
& =\frac{1}{2}\left(\left|\frac{3 u}{4}-\frac{1}{2}\right|+\left|\frac{3 v}{4}-\frac{1}{2}\right|\right) \\
& \geq \frac{1}{2}\left|\left(\frac{3 u}{4}-\frac{1}{2}\right)-\left(\frac{3 v}{4}-\frac{1}{2}\right)\right|=\frac{3}{8}|u-v| \\
& \geq \frac{1}{4}|u-v|=\|T(u)-T(v)\| .
\end{aligned}
$$

(iii) Let $u \in[0,1 / 4)$ and $v \in[1 / 4,1]$, and we have

$$
\begin{aligned}
\frac{1}{2} & (\|T(u)-u\|+\|T(v)-v\|) \\
& =\frac{1}{2}\left(\left|\frac{3 u}{2}-1\right|+\left|\frac{3 v}{4}-\frac{1}{2}\right|\right) \\
& \geq \frac{1}{2}\left|\left(\frac{3 u}{2}-1\right)+\left(\frac{3 v}{4}-\frac{1}{2}\right)\right|=\frac{3}{8}|2-2 u-v| \\
& \geq \frac{1}{4}|2-2 u-v|=\|T(u)-T(v)\| .
\end{aligned}
$$

Therefore, $T$ is monotone Reich-Suzuki type nonexpansive mapping with unique fixed point $2 / 3$.

Notice that the space considered in the above example was a linear space. Now we present an example of a hyperbolic space which is not linear. Therefore it is a nontrivial example of a hyperbolic space.

Example 18. Let $E=\left\{\left(u_{1}, u_{2}\right) \in \mathbb{R}^{2} ; u_{1}, u_{2}>0\right\}$. Define $\rho$ : $E \times E \rightarrow[0, \infty)$ by

$$
\rho(u, v)=\left|u_{1}-v_{1}\right|+\left|u_{1} u_{2}-v_{1} v_{2}\right|
$$


for all $u=\left(u_{1}, u_{2}\right)$ and $v=\left(v_{1}, v_{2}\right)$ in $E$. Then it can be easily seen that $(E, \rho)$ is a metric space. Now, for $\beta \in[0,1]$, define a function $H: E \times E \times[0,1] \rightarrow E$ by

$$
\begin{aligned}
& H(u, v, \beta) \\
& \quad=\left((1-\beta) u_{1}+\beta v_{1}, \frac{(1-\beta) u_{1} u_{2}+\beta v_{1} v_{2}}{(1-\beta) u_{1}+\beta v_{1}}\right) .
\end{aligned}
$$

We show that $(E, \rho, H)$ is a hyperbolic metric space. For $u=$ $\left(u_{1}, u_{2}\right), v=\left(v_{1}, v_{2}\right), z=\left(z_{1}, z_{2}\right)$, and $w=\left(w_{1}, w_{2}\right)$ in $E$, consider the following:

(K1)

$$
\begin{aligned}
d(z, H(u, v, \beta))= & \left|z_{1}-(1-\beta) u_{1}-\beta v_{1}\right| \\
& +\left|z_{1} z_{2}-(1-\beta) u_{1} u_{2}-\beta v_{1} v_{2}\right| \\
\leq & (1-\beta)\left|z_{1}-u_{1}\right|+\beta\left|z_{1}-v_{1}\right| \\
& +(1-\beta)\left|z_{1} z_{2}-u_{1} u_{2}\right| \\
& +\beta\left|z_{1} z_{2}-v_{1} v_{2}\right| \\
= & (1-\beta) d(z, u)+\beta d(z, v) .
\end{aligned}
$$

(K2)

$$
\begin{aligned}
d( & H(u, v, \beta), H(u, v, \gamma)) \\
= & \left|(1-\beta) u_{1}+\beta v_{1}-(1-\gamma) u_{1}-\gamma v_{1}\right| \\
& \quad+\left|(1-\beta) u_{1} u_{2}+\beta v_{1} v_{2}-(1-\gamma) u_{1} u_{2}-\gamma v_{1} v_{2}\right| \\
= & |\beta-\gamma|\left(\left|u_{1}-v_{1}\right|+\left|u_{1} u_{2}-v_{1} v_{2}\right|\right) \\
= & |\beta-\gamma| d(u, v) .
\end{aligned}
$$

(K3)

$$
\begin{aligned}
H & (u, v, \beta) \\
& =\left((1-\beta) u_{1}+\beta v_{1}, \frac{(1-\beta) u_{1} u_{2}+\beta v_{1} v_{2}}{(1-\beta) u_{1}+\beta v_{1}}\right) \\
& =\left(\beta v_{1}+(1-\beta) u_{1}, \frac{\beta v_{1} v_{2}+(1-\beta) u_{1} u_{2}}{\beta v_{1}+(1-\beta) u_{1}}\right) \\
& =H(v, u, 1-\beta) .
\end{aligned}
$$

(K4)

$$
\begin{aligned}
d & (H(u, z, \beta), H(v, w, \beta)) \\
= & \left|(1-\beta) u_{1}+\beta z_{1}-(1-\beta) v_{1}-\beta w_{1}\right| \\
& \quad+\left|(1-\beta) u_{1} u_{2}+\beta z_{1} z_{2}-(1-\beta) v_{1} v_{2}-\beta w_{1} w_{2}\right| \\
\leq & (1-\beta)\left(\left|u_{1}-v_{1}\right|+\left|u_{1} u_{2}-v_{1} v_{2}\right|\right) \\
& \quad+\beta\left(\left|z_{1}-w_{1}\right|+\left|z_{1} z_{2}-w_{1} w_{2}\right|\right) \\
= & (1-\beta) d(u, v)+\beta d(z, w) .
\end{aligned}
$$

Therefore, $(E, \rho, H)$ is a hyperbolic metric space but not a normed linear space. Now, let us define an order on $E$ as follows: for $u=\left(u_{1}, u_{2}\right)$ and $v=\left(v_{1}, v_{2}\right), u \preceq v$ if and only if $u_{1}<v_{1}$ or $u_{1}=v_{1}$ and $u_{2} \leq v_{2}$. Thus $(E, \rho, \preceq)$ is an ordered hyperbolic metric space.

Let $K:=[1,4] \times[1,4] \subset E$ and $T: K \rightarrow K$ be a mapping defined by

$$
T\left(u_{1}, u_{2}\right)= \begin{cases}(1,1), & \text { if }\left(u_{1}, u_{2}\right) \neq(4,4) \\ \left(\frac{3}{2}, \frac{3}{2}\right), & \text { if }\left(u_{1}, u_{2}\right)=(4,4) .\end{cases}
$$

First we show that $T$ is not a nonexpansive mapping on $K$. Let $u=(1,1)$ and $v=(4,4)$. Then

$$
\rho(T(u), T(v))=\frac{7}{4}>18=\rho(u, v) .
$$

Now, we show that $T$ is monotone Reich-Suzuki type nonexpansive mapping for $k=1 / 2$. We consider the following cases.

Case i. If $u=\left(u_{1}, u_{2}\right)$ and $v=\left(v_{1}, v_{2}\right) \neq(4,4)$, then

$$
\rho(T(u), T(v))=0 \leq \frac{1}{2}(\rho(u, T(u))+\rho(v, T(v))) .
$$

Case ii. If $u=\left(u_{1}, u_{2}\right) \neq(4,4)$ and $v=\left(v_{1}, v_{2}\right)=(4,4)$, then

$$
\begin{aligned}
\frac{1}{2} & (\rho(u, T(u))+\rho(v, T(v))) \\
& =\frac{1}{2}\left[\left|u_{1}-1\right|+\left|u_{1} u_{2}-1\right|\right]+\frac{1}{2}\left[\frac{5}{2}+\frac{55}{4}\right] \\
& =\frac{1}{2}\left[u_{1}-1+u_{1} u_{2}-1\right]+\frac{65}{8}>\frac{7}{4} \\
& =\rho(T(u), T(v)) .
\end{aligned}
$$

Therefore $T$ is monotone Reich-Suzuki type nonexpansive mapping. The only fixed point of $T$ is $(1,1)$.

\section{Convergence Results}

In this section, we discuss some strong convergence and $\Delta$ convergence results in a partially ordered hyperbolic space for Abbas and Nazir iteration algorithm [27]. Our results are prefaced by the following proposition and lemma.

Proposition 19. Let $(E, \rho, \preceq)$ be a partially ordered hyperbolic metric space and $K$ a nonempty subset of $E$. Let $T: K \rightarrow K$ be a monotone Reich-Suzuki type nonexpansive mapping with a fixed point $z \in K$. Then $T$ is quasi-nonexpansive; that is, $\rho(T(u), z) \leq \rho(u, z)$ for all $u \in K$ and $z \in F(T)$ such that $u$ and $z$ are comparable.

Lemma 20 (see [34]). Let $(E, \rho)$ be a uniformly convex hyperbolic metric space with monotone modulus of uniform convexity $\delta$. Let $z \in E$ and $\left\{\alpha_{n}\right\}$ be a sequence such that $0<a \leq \alpha_{n} \leq b<1$. If $\left\{u_{n}\right\}$ and $\left\{v_{n}\right\}$ are sequences in $E$ such that $\limsup _{n \rightarrow \infty} \rho\left(u_{n}, z\right) \leq r, \limsup _{n \rightarrow \infty} \rho\left(v_{n}, z\right) \leq r$, and $\lim _{n \rightarrow \infty} \rho\left(\alpha_{n} v_{n} \oplus\left(1-\alpha_{n}\right) u_{n}, z\right)=r$ for some $r \geq 0$, then we have $\lim _{n \rightarrow \infty} \rho\left(u_{n}, v_{n}\right)=0$ 
Theorem 21. Let $(E, \rho, \preceq)$ be a uniformly convex partially ordered hyperbolic metric space and $K$ a nonempty closed convex subset of E. Let $T: K \rightarrow K$ be a monotone ReichSuzuki type nonexpansive mapping. Assume that there exists $u_{1} \in K$ such that $u_{1}$ and $T\left(u_{1}\right)$ are comparable. Suppose $F(T)$ is nonempty, and $u_{1}$ and $z$ are comparable for every $z \in F(T)$. Let $\left\{u_{n}\right\}$ be a sequence defined by (13). Then the following assertions hold:

(i) The sequence $\left\{u_{n}\right\}$ is bounded.

(ii) $\max \left\{\rho\left(u_{n+1}, z\right), \rho\left(v_{n}, z\right), \rho\left(w_{n}, z\right)\right\} \leq \rho\left(u_{n}, z\right)$ for all $n \in \mathbb{N}$.

(iii) $\lim _{n \rightarrow \infty} \rho\left(u_{n}, z\right)$ exists and $\lim _{n \rightarrow \infty} \operatorname{dist}\left(u_{n}, F(T)\right)$ exists, where dist $(u, F(T))$ denotes the distance from $u$ to $F(T)$.

(iv) $\lim _{n \rightarrow \infty} \rho\left(T\left(u_{n}\right), u_{n}\right)=0$.

Proof. Without loss of generality, we may assume that $u_{1} \leq z$. Since $T$ is monotone, $T\left(u_{1}\right) \preceq T(z)=z$. By (13) (as in (16) and (17)), we have

$$
u_{1} \preceq w_{1} \preceq T\left(u_{1}\right) \preceq v_{1} \preceq T\left(w_{1}\right) .
$$

So, $w_{1} \preceq z$. By monotonicity of $T$,

$$
T\left(w_{1}\right) \preceq T(z)=z,
$$

and also, from (58), we have $v_{1} \preceq z$. By monotonicity of $T$,

$$
T\left(v_{1}\right) \preceq T(z)=z .
$$

By (13) (as in (18)),

$$
T\left(w_{1}\right) \preceq u_{2} \preceq T\left(v_{1}\right) .
$$

From (60) and (61), we have $u_{2} \leq z$, so, by monotonicity of $T$,

$$
T\left(u_{2}\right) \preceq T(z)=z .
$$

Again from (31) and (62), for $n=2$, we have

$$
u_{2} \preceq T\left(u_{2}\right) \preceq z .
$$

Applying the same argument, we get

$$
u_{n} \preceq T\left(u_{n}\right) \preceq z .
$$

Now, by (13) and Proposition 19, we have

$$
\begin{aligned}
\rho\left(w_{n}, z\right) & =\rho\left(\left(1-\gamma_{n}\right) u_{n} \oplus \gamma_{n} T\left(u_{n}\right), z\right) \\
& \leq\left(1-\gamma_{n}\right) \rho\left(u_{n}, z\right)+\gamma_{n} \rho\left(T\left(u_{n}\right), z\right) \\
& \leq\left(1-\gamma_{n}\right) \rho\left(u_{n}, z\right)+\gamma_{n} \rho\left(u_{n}, z\right) \\
& =\rho\left(u_{n}, z\right) .
\end{aligned}
$$

By (13), (65), and Proposition 19, we have

$$
\begin{aligned}
\rho\left(v_{n}, z\right) & =\rho\left(\left(1-\beta_{n}\right) T\left(u_{n}\right) \oplus \beta_{n} T\left(w_{n}\right), z\right) \\
& \leq\left(1-\beta_{n}\right) \rho\left(T\left(u_{n}\right), z\right)+\beta_{n} \rho\left(T\left(w_{n}\right), z\right) \\
& \leq\left(1-\beta_{n}\right) \rho\left(u_{n}, z\right)+\beta_{n} \rho\left(w_{n}, z\right) \\
& \leq\left(1-\beta_{n}\right) \rho\left(u_{n}, z\right)+\beta_{n} \rho\left(u_{n}, z\right) \\
& =\rho\left(u_{n}, z\right) .
\end{aligned}
$$

By (13), (65), (66), and Proposition 19, we have

$$
\begin{aligned}
\rho\left(u_{n+1}, z\right) & =\rho\left(\left(1-\alpha_{n}\right) T\left(v_{n}\right) \oplus \alpha_{n} T\left(w_{n}\right), z\right) \\
& \leq\left(1-\alpha_{n}\right) \rho\left(T\left(v_{n}\right), z\right)+\alpha_{n} \rho\left(T\left(w_{n}\right), z\right) \\
& \leq\left(1-\alpha_{n}\right) \rho\left(v_{n}, z\right)+\alpha_{n} \rho\left(w_{n}, z\right) \\
& \leq\left(1-\alpha_{n}\right) \rho\left(u_{n}, z\right)+\alpha_{n} \rho\left(u_{n}, z\right) \\
& =\rho\left(u_{n}, z\right) .
\end{aligned}
$$

Thus, the sequence $\left\{\rho\left(u_{n}, z\right)\right\}$ is bounded and decreasing, so, $\lim _{n \rightarrow \infty} \rho\left(u_{n}, z\right)$ exists. For each $z \in F(T)$ and $n \in \mathbb{N}$ we have $\rho\left(u_{n+1}, z\right) \leq \rho\left(u_{n}, z\right)$. Taking infimum over all $z \in F(T)$, we get $\operatorname{dist}\left(u_{n+1}, F(T)\right) \leq \operatorname{dist}\left(u_{n}, F(T)\right)$ for all $n \in \mathbb{N}$. So the sequence $\operatorname{dist}\left(u_{n}, F(T)\right)$ is bounded and decreasing. Therefore $\lim _{n \rightarrow \infty} \operatorname{dist}\left(u_{n}, F(T)\right)$ exists. Suppose

$$
\lim _{n \rightarrow \infty} \rho\left(u_{n}, z\right)=r .
$$

From (68) and Proposition 19, we have

$$
\limsup _{n \rightarrow \infty} \rho\left(T\left(u_{n}\right), z\right) \leq r .
$$

By (65) and (68), we have

$$
\limsup _{n \rightarrow \infty} \rho\left(w_{n}, z\right) \leq r .
$$

From (70) and Proposition 19, we have

$$
\limsup _{n \rightarrow \infty} \rho\left(T\left(w_{n}\right), z\right) \leq r .
$$

By (66) and (68), we have

$$
\limsup _{n \rightarrow \infty} \rho\left(v_{n}, z\right) \leq r .
$$

By (72) and Proposition 19, we have

$$
\limsup _{n \rightarrow \infty} \rho\left(T\left(v_{n}\right), z\right) \leq r .
$$

By (68) and (13), we have

$$
\begin{aligned}
r & =\lim _{n \rightarrow \infty} \rho\left(u_{n+1}, z\right) \\
& =\lim _{n \rightarrow \infty} \rho\left(\left(1-\alpha_{n}\right) T\left(v_{n}\right) \oplus \alpha_{n} T\left(w_{n}\right), z\right) .
\end{aligned}
$$

In view of (71), (73), (74), and Lemma 20, we have

$$
\lim _{n \rightarrow \infty} \rho\left(T\left(v_{n}\right), T\left(w_{n}\right)\right)=0 .
$$

By (13),

$$
\begin{aligned}
& \rho\left(u_{n+1}, T\left(w_{n}\right)\right) \\
& \quad=\rho\left(\left(1-\alpha_{n}\right) T\left(v_{n}\right) \oplus \alpha_{n} T\left(w_{n}\right), T\left(w_{n}\right)\right) \\
& \quad \leq\left(1-\alpha_{n}\right) \rho\left(T\left(v_{n}\right), T\left(w_{n}\right)\right),
\end{aligned}
$$

letting $n \rightarrow \infty$ and using (75), we have

$$
\lim _{n \rightarrow \infty} \rho\left(u_{n+1}, T\left(w_{n}\right)\right)=0 .
$$


By triangle inequality and Proposition 19, we have

$$
\begin{aligned}
\rho\left(u_{n+1}, z\right) & \leq \rho\left(u_{n+1}, T\left(w_{n}\right)\right)+\rho\left(T\left(w_{n}\right), z\right) \\
& \leq \rho\left(u_{n+1}, T\left(w_{n}\right)\right)+\rho\left(w_{n}, z\right),
\end{aligned}
$$

and as $n \rightarrow \infty$, we have

$$
r \leq \liminf _{n \rightarrow \infty} \rho\left(w_{n}, z\right) .
$$

By (70) and (79), we have

$$
r=\lim _{n \rightarrow \infty} \rho\left(w_{n}, z\right),
$$

or

$$
\begin{aligned}
r & =\lim _{n \rightarrow \infty} \rho\left(w_{n}, z\right) \\
& =\lim _{n \rightarrow \infty} \rho\left(\left(1-\gamma_{n}\right) u_{n} \oplus \gamma_{n} T\left(u_{n}\right), z\right) .
\end{aligned}
$$

Finally, from (68), (69), (81), and Lemma 20, we conclude that $\lim _{n \rightarrow \infty} \rho\left(T\left(u_{n}\right), u_{n}\right)=0$.

Now, we present the following main result about $\Delta$ convergence.

Theorem 22. Let $(E, \rho, \preceq)$ be a uniformly convex partially ordered hyperbolic metric space and $K$ a nonempty closed convex subset of $E$. Let $T: K \rightarrow K$ be a monotone ReichSuzuki type nonexpansive mapping. Assume that there exists $u_{1} \in K$ such that $u_{1}$ and $T\left(u_{1}\right)$ are comparable and $F(T)$ is nonempty and totally ordered. Then the sequence $\left\{u_{n}\right\}$ defined by (13) $\Delta$-converges to a fixed point of $T$.

Proof. By Theorem 21, the sequence $\left\{u_{n}\right\}$ is bounded. Therefore there exists a subsequence $\left\{u_{n_{k}}\right\}$ of $\left\{u_{n}\right\}$ such that $\left\{u_{n_{k}}\right\} \Delta$ converges to some $p \in K$. By Lemma 13, we have

$$
u_{1} \preceq u_{n_{k}} \preceq p \quad \forall k \in \mathbb{N} .
$$

Now, we show that every $\Delta$-convergent subsequence of $\left\{u_{n}\right\}$ has a unique $\Delta$-limit in $F(T)$. Suppose $\left\{u_{n}\right\}$ has two subsequences $\left\{u_{n_{k}}\right\}$ and $\left\{u_{n_{r}}\right\} \Delta$-converging to $l$ and $m$, respectively. By Theorem 21, $\left\{u_{n_{k}}\right\}$ is bounded and

$$
\lim _{k \rightarrow \infty} \rho\left(T\left(u_{n_{k}}\right), u_{n_{k}}\right)=0 .
$$

We claim that $l \in F(T)$. Let $\tau: K \rightarrow[0, \infty)$ be a type function generated by $\left\{u_{n_{k}}\right\}$; that is,

$$
\tau(u)=\limsup _{k \rightarrow \infty} \rho\left(u_{n_{k}}, l\right) .
$$

By Lemma 15 and (83), we have

$$
\begin{aligned}
\tau(T(l))= & \limsup _{k \rightarrow \infty} \rho\left(u_{n_{k}}, T(l)\right) \\
\leq & \frac{(3+k)}{(1-k)} \limsup _{k \rightarrow \infty} \rho\left(u_{n_{k}}, T\left(u_{n_{k}}\right)\right) \\
& +\limsup _{k \rightarrow \infty} \rho\left(u_{n_{k}}, l\right) \leq \tau(l) .
\end{aligned}
$$

By the uniqueness of the element $l$ and definition of $\Delta$ convergence, $T(l)=l$. Similarly $T(m)=m$. By the definition of $\Delta$-convergence and Lemma 10 , we have

$$
\begin{aligned}
\limsup _{n \rightarrow \infty} \rho\left(u_{n}, l\right) & =\limsup _{k \rightarrow \infty} \rho\left(u_{n_{k}}, l\right) \\
& <\limsup _{k \rightarrow \infty} \rho\left(u_{n_{k}}, m\right) \\
& =\limsup _{n \rightarrow \infty} \rho\left(u_{n}, m\right) \\
& =\limsup _{r \rightarrow \infty} \rho\left(u_{n_{r}}, m\right) \\
& <\limsup _{r \rightarrow \infty} \rho\left(u_{n_{r}}, l\right) \\
& =\limsup _{n \rightarrow \infty} \rho\left(u_{n}, l\right),
\end{aligned}
$$

which is a contradiction, unless $l=m$.

Next, we present a strong convergence theorem.

Theorem 23. Let $(E, \rho, \preceq)$ be a uniformly convex partially ordered hyperbolic metric space and $K, T$, and $\left\{u_{n}\right\}$ be the same as in Theorem 21 with $F(T) \neq \emptyset$. The sequence defined by (13) converges strongly to a fixed point of $T$ if and only if $\lim \inf _{n \rightarrow \infty} \operatorname{dist}\left(u_{n}, F(T)\right)=0$, provided $F(T)$ is a totally ordered set.

Proof. Suppose that $\liminf _{n \rightarrow \infty} \operatorname{dist}\left(u_{n}, F(T)\right)=0$. From Theorem 21, $\lim _{n \rightarrow \infty} \operatorname{dist}\left(u_{n}, F(T)\right)$ exists, so

$$
\lim _{n \rightarrow \infty} \operatorname{dist}\left(u_{n}, F(T)\right)=0 .
$$

First we show that the set $F(T)$ is closed. For this, let $\left\{z_{n}\right\}$ be a sequence in $F(T)$ converging to a point $v \in K$. Since $(1 / 2) \rho\left(z_{n}, T\left(z_{n}\right)\right)=0 \leq \rho\left(z_{n}, v\right)$ for all $n \in \mathbb{N}$, we have

$$
\begin{aligned}
\rho\left(T\left(z_{n}\right), T(v)\right)= & \rho\left(z_{n}, T(v)\right) \\
\leq & k \rho\left(T\left(z_{n}\right), z_{n}\right)+k \rho(T(v), v) \\
& +(1-2 k) \rho\left(z_{n}, v\right) \\
\leq & k \rho\left(T(v), z_{n}\right)+k \rho\left(z_{n}, v\right) \\
& +(1-2 k) \rho\left(z_{n}, v\right) .
\end{aligned}
$$

As $1-k>0$,

$$
\rho\left(z_{n}, T(v)\right) \leq \rho\left(z_{n}, v\right)
$$

and hence

$$
\limsup _{n \rightarrow \infty} \rho\left(z_{n}, T(v)\right) \leq \limsup _{n \rightarrow \infty} \rho\left(z_{n}, v\right)=0 .
$$

Then, $\left\{z_{n}\right\}$ converges strongly to $T(v)$. This implies that $T(v)=$ $v$. Therefore $F(T)$ is a closed set. In view of (87), let $\left\{u_{n_{k}}\right\}$ be a subsequence of sequence $\left\{u_{n}\right\}$ such that $\rho\left(u_{n_{k}}, z_{k}\right) \leq 1 / 2^{k}$ for 
all $k \geq 1$, where $\left\{z_{k}\right\}$ is a sequence in $F(T)$. By Theorem 21 , we have

$$
\rho\left(u_{n_{k+1}}, z_{k}\right) \leq \rho\left(u_{n_{k}}, z_{k}\right) \leq \frac{1}{2^{k}} .
$$

Now, by the triangle inequality and (91), we have

$$
\begin{aligned}
\rho\left(z_{k+1}, z_{k}\right) & \leq \rho\left(z_{k+1}, u_{n_{k+1}}\right)+\rho\left(u_{n_{k+1}}, z_{k}\right) \\
& \leq \frac{1}{2^{k+1}}+\frac{1}{2^{k}}<\frac{1}{2^{k-1}} .
\end{aligned}
$$

A standard argument shows that $\left\{z_{k}\right\}$ is a Cauchy sequence. Since $F(T)$ is closed, $\left\{z_{k}\right\}$ converges to some point $v \in F(T)$. Now

$$
\rho\left(u_{n_{k}}, v\right) \leq \rho\left(u_{n_{k}}, z_{k}\right)+\rho\left(z_{k}, v\right) \text {. }
$$

Letting $k \rightarrow \infty$ implies that $\left\{u_{n_{k}}\right\}$ converges strongly to $v$. By Theorem $21, \lim _{n \rightarrow \infty} \rho\left(u_{n}, v\right)$ exists. Hence $\left\{u_{n}\right\}$ converges strongly to $v$. The converse is obvious; hence the proof is completed.

Theorem 24. Let $(E, \rho, \preceq)$ be a uniformly convex partially ordered hyperbolic metric space and, $T$, and $\left\{u_{n}\right\}$ be the same as in Theorem 21. Let $T$ satisfy the condition $(I)$ and $F(T) \neq \emptyset$. Then $\left\{u_{n}\right\}$ converges strongly to a fixed point of $T$.

Proof. From Theorem 21, it follows that

$$
\liminf _{n \rightarrow \infty} \rho\left(T\left(u_{n}\right), u_{n}\right)=0
$$

As $T$ satisfies condition $(I)$, we have $\rho\left(T\left(u_{n}\right), u_{n}\right) \quad \geq$ $g\left(\operatorname{dist}\left(u_{n}, F(T)\right)\right)$. From (94), we have

$$
\liminf _{n \rightarrow \infty} g\left(\operatorname{dist}\left(u_{n}, F(T)\right)\right)=0 .
$$

Since $g:[0, \infty) \rightarrow[0, \infty)$ is a nondecreasing function with $g(0)=0$ and $g(r)>0$ for all $r \in(0, \infty)$, therefore we have

$$
\liminf _{n \rightarrow \infty} \operatorname{dist}\left(u_{n}, F(T)\right)=0 .
$$

Therefore all the assumptions of Theorem 23 are satisfied and $\left\{u_{n}\right\}$ converges strongly to a fixed point of $T$.

\section{Applications to Nonlinear Integral Equations}

In this section, we present an application of our results to nonlinear integral equations.

We give an existence theorem in an ordered Banach space. These spaces are a special case of partially ordered hyperbolic spaces.

Theorem 25. Let $E$ be an ordered Banach space and $K$ be a nonempty compact subset of $E$. Let $T: K \rightarrow K$ be a monotone Reich-Suzuki type nonexpansive mapping. Assume that there exists an a.f.p.s. $\left\{u_{n}\right\}$. Then $T$ has a fixed point.

Proof. It may be completed following Theorem 16 and [26, Theorem 4].
Consider the integral equation

$$
\begin{aligned}
& u(t)=h(t)+\lambda \int_{0}^{1} k(t, s) f(s, u(s)) d s, \\
& \quad t \in I=[0,1], \quad \lambda \geq 0 .
\end{aligned}
$$

Now, we present the following result (see also [35]).

Theorem 26. Let $X=C[0,1]$, the space of continuous functions on $I=[0,1]$ with ordered relation ' $\preceq$ ' in $X$ defined as, for all $u, v \in X, u \preceq v$ if and only if $u(t) \leq v(t), \forall t \in$ $[0,1]$. Suppose $X$ is equipped with supremum norm defined by $\|u-v\|=\sup _{t \in I}|u(t)-v(t)|$ and $F$ is a compact subset of $X$. Assume that the following conditions hold:

(a) $h: I \rightarrow \mathbb{R}$ is continuous

(b) $f: I \times F \rightarrow F$ is continuous, $f(t, u) \geq 0$, and there exists a constant $L \geq 0$ such that, for all $u, v \in F$,

$$
|f(t, u)-f(t, v)| \leq L|u(t)-v(t)| .
$$

(c) $k: I \times F \rightarrow \mathbb{R}$ is continuous such that $k(t, u) \geq 0$, and $\int_{0}^{1} k(t, s) d s \leq K$ for all $(t, u) \in I \times F$.

(d) $\lambda K L=1$.

(e) $T: F \rightarrow F$ is a mapping defined by

$$
\begin{array}{rl}
T u(t)=h(t)+\lambda \int_{0}^{1} k(t, s) f(s, u(s)) d s, & \\
t & t=[0,1], \lambda \geq 0 .
\end{array}
$$

Then, the nonlinear integral equation (97) has a solution in $C[0,1]$, if $T$ admits an a.f.p.s.

Proof. For $u, v \in F$ such that $u \preceq v$, we have

$$
\begin{aligned}
& |T u(t)-T v(t)| \\
& =\mid\left(h(t)+\lambda \int_{0}^{1} k(t, s) f(s, u(s)) d s\right) \\
& -\left(h(t)+\lambda \int_{0}^{1} k(t, s) f(s, v(s)) d s\right) \mid \\
& =\lambda\left|\int_{0}^{1} k(t, s)(f(s, u(s))-f(s, v(s))) d s\right| \\
& \leq \lambda \int_{0}^{1} k(t, s)|f(s, u(s))-f(s, v(s))| d s \\
& \leq \lambda \int_{0}^{1} k(t, s) L[v(s)-u(s)] d s .
\end{aligned}
$$

Taking the supremum norm on both sides, we have

$$
\|T(u)-T(v)\| \leq \lambda K L\|u-v\|=\|u-v\| .
$$

i.e., $T$ is monotone nonexpansive. Hence, $T$ is monotone Reich-Suzuki type nonexpansive mapping with $k=0$. Therefore all the assumptions of Theorem 25 have been satisfied, so (97) has a solution in $F \subseteq C[0,1]$. 
Now, let us introduce the following computational example.

Example 27. Consider the following functional integral equation:

$$
\begin{aligned}
u(t)= & {\left[\cos \left(\frac{\pi}{2} t\right)-\frac{8(\pi-1)}{3 \pi^{2}} t\right] } \\
& +\frac{20}{9} \int_{0}^{1}\left(\frac{3 t(1+s)}{5}\right) \frac{|u(s)|}{2} d s, \quad t \in[0,1] .
\end{aligned}
$$

It is observed that the above integral equation is a special case of (97) with

$$
\begin{aligned}
h(t) & =\cos \left(\frac{\pi}{2} t\right)-\frac{8(\pi-1)}{3 \pi^{2}} t \\
k(t, s) & =\frac{3 t(1+s)}{5} \text { and } \\
f(t, u) & =\frac{|u(t)|}{2} .
\end{aligned}
$$

Now, for arbitrary $u, v \in C(I, \mathbb{R})$ with $u(t) \leq v(t)$ for $t \in I=$ $[0,1]$, we have

$$
\begin{aligned}
|f(t, u)-f(t, v)| & =\frac{1}{2}|| u(t)|-| v(t)|| \\
& \leq \frac{1}{2}|u(t)-v(t)| .
\end{aligned}
$$

As $h$ is continuous and for $t \in[0,1]$, we have

$$
\int_{0}^{1} k(t, s) d s=\int_{0}^{1} \frac{3 t(1+s)}{5} d s=\frac{9}{10} t \leq \frac{9}{10} .
$$

Consequently, all the conditions of Theorem 26 are satisfied with $L=1 / 2, K=9 / 10$, and $\lambda=20 / 9(L K \lambda=1)$, so there exists a solution of integral equation (102). It can be easily verified that $u(t)=\cos ((\pi / 2) t)$ is a solution of nonlinear integral equation (102).

\section{Data Availability}

No data were used to support this study.

\section{Conflicts of Interest}

The authors declare that they do not have any conflicts of interest.

\section{Acknowledgments}

The third author gratefully acknowledges with thanks the Department of Research Affairs at UAEU. This article is supported by Grant UPAR (11) 2016, Fund no. 31S249 (COS).

\section{References}

[1] K. Menger, "Untersuchungen über allgemeine Metrik," Mathematische Annalen, vol. 100, no. 1, pp. 75-163, 1928.
[2] S. Reich and I. Shafrir, "Nonexpansive iterations in hyperbolic spaces," Nonlinear Analysis. Theory, Methods \& Applications. An International Multidisciplinary Journal, vol. 15, no. 6, pp. 537$558,1990$.

[3] W. A. Kirk, "Fixed point theory for nonexpansive mappings," in Fixed Point Theory (Sherbrooke, Que., 1980), vol. 886 of Lecture Notes in Math, pp. 484-505, Springer, New York,NY, USA, 1981.

[4] W. A. Kirk, "Fixed point theorems in CAT(0) spaces and Rtrees," Fixed Point Theory and Applications, no. 4, pp. 309-316, 2004.

[5] L. Leustean, "A quadratic rate of asymptotic regularity for CAT(0)-spaces," Journal of Mathematical Analysis and Applications, vol. 325, no. 1, pp. 386-399, 2007.

[6] H. Busemann, "Spaces with non-positive curvature," Acta Mathematica, vol. 80, pp. 259-310, 1948.

[7] K. Goebel and S. Reich, "Uniform convexity, hyperbolic geometry and nonexpansive mappings," in Monographs and Textbooks in Pure and Applied Mathematics, vol. 83, Marcel Dekker, New York, NY, USA, 1984.

[8] B. A. Bin Dehaish and M. A. Khamsi, "Browder and Göhde fixed point theorem for monotone nonexpansive mappings," Fixed Point Theory and Applications, vol. 9, no. 20, 2016.

[9] K. Goebel and W. A. Kirk, "Iteration processes for nonexpansive mappings," in Topological Methods in Nonlinear Functional Analysis, S. P. Singh, S. Thomeier, and B. Watson, Eds., vol. 21 of Contemporary Mathematics, pp. 115-123, American Mathematical Society, Providence, RI, USA, 1983.

[10] M. Gromov, Metric structures for riemannian and nonriemannian spaces, Modern Birkhäuser Classics, Birkhäuser Boston, Inc., Boston, MA, USA, 2007, With appendices by M. Katz, P. Pansu and S. Semmes, Translated from the French by Sean Michael Bates.

[11] U. Kohlenbach, "Some logical metatheorems with applications in functional analysis," Transactions of the American Mathematical Society, vol. 357, no. 1, pp. 89-128, 2005.

[12] L. Leustean, "Nonexpansive iterations in uniformly convexWhyperbolic spaces, Nonlinear analysis and optimization I. Nonlinear analysis," in Contemporary Math, vol. 513, pp. 193-210, American Mathematical Society, Providence, RI, USA, 2010.

[13] S. A. Naimpally, K. L. Singh, and J. H. Whitfield, "Fixed points in convex metric spaces," Mathematica Japonica, vol. 29, no. 4, pp. 585-597, 1984.

[14] W. Takahashi, "A convexity in metric space and nonexpansive mappings," I, Kodai Mathematical Seminar Reports, vol. 22, pp. $142-149,1970$.

[15] A. Amini-Harandi, M. Fakhar, and H. R. Hajisharifi, "Weak fixed point property for nonexpansive mappings with respect to orbits in Banach spaces," Journal of Fixed Point Theory and Applications, vol. 18, no. 3, pp. 601-607, 2016.

[16] K. Aoyama and F. Kohsaka, "Fixed point theorem foranonexpansive mappings in Banach spaces," Nonlinear Analysis, vol. 2011, no. 13, Article ID 2810735, pp. 4387-4391, 2011.

[17] T. Butsan, S. Dhompongsa, and W. Takahashi, "A fixed point theorem for pointwise eventually nonexpansive mappings in nearly uniformly convex Banach spaces," Nonlinear Analysis. Theory, Methods \& Applications, vol. 74, no. 5, pp. 1694-1701, 2011.

[18] J. Garca-Falset, E. Llorens-Fuster, and T. Suzuki, "Fixed point theory for a class of generalized nonexpansive mappings," Journal of Mathematical Analysis and Applications, vol. 375, no. 1, pp. 185-195, 2011. 
[19] K. Goebel and M. Japón-Pineda, "A new type of nonexpansiveness," in Proceedings of the 8th International Conference on Fixed Point Theory and Applications, Chiang Mai, Thailand, 2007.

[20] K. Goebel and W. A. Kirk, "A fixed point theorem for asymptotically nonexpansive mappings," Proceedings of the American Mathematical Society, vol. 35, pp. 171-174, 1972.

[21] J. Greguš, "A fixed point theorem in Banach space," Unione Matematica Italiana. Bollettino. A. Serie V, vol. 17, no. 1, pp. 193$198,1980$.

[22] W. A. Kirk, "Fixed point theorems for non-Lipschitzian mappings of asymptotically nonexpansive type," Israel Journal of Mathematics, vol. 17, pp. 339-346, 1974.

[23] E. Llorens-Fuster, "Orbitally nonexpansive mappings," Bulletin of the Australian Mathematical Society, vol. 93, no. 3, pp. 497503, 2016.

[24] A. Nicolae, "Generalized asymptotic pointwise contractions and nonexpansive mappings involving orbits," Fixed Point Theory and Applications, Art. ID 458265, 19 pages, 2010.

[25] R. Pant and R. Shukla, "Approximating fixed points of generalized $\alpha$-nonexpansive mappings in Banach spaces," Numerical Functional Analysis and Optimization, vol. 38, no. 2, pp. 248266, 2017.

[26] T. Suzuki, "Fixed point theorems and convergence theorems for some generalized nonexpansive mappings," Journal of Mathematical Analysis and Applications, vol. 340, no. 2, pp. 1088-1095, 2008.

[27] M. Abbas and T. Nazir, "A new faster iteration process applied to constrained minimization and feasibility problems," Matematicki Vesnik, vol. 66, no. 2, pp. 223-234, 2014.

[28] K. Goebel, T. Sekowski, and A. Stachura, "Uniform convexity of the hyperbolic metric and fixed points of holomorphic mappings in the Hilbert ball," Nonlinear Analysis: Theory, Methods \& Applications, vol. 4, no. 5, pp. 1011-1021, 1980.

[29] M. A. Khamsi and A. R. Khan, "Inequalities in metric spaces with applications," Nonlinear Analysis. Theory, Methods \& Applications. An International Multidisciplinary Journal, vol. 74, no. 12, pp. 4036-4045, 2011.

[30] M. A. Khamsi, "On metric spaces with uniform normal structure," Proceedings of the American Mathematical Society, vol. 106, no. 3, pp. 723-726, 1989.

[31] H. F. Senter and J. Dotson, "Approximating fixed points of nonexpansive mappings," Proceedings of the American Mathematical Society, vol. 44, pp. 375-380, 1974.

[32] T. C. Lim, "Remarks on some fixed point theorems," Proceedings of the American Mathematical Society, vol. 60, pp. 179-182 (1977), 1976.

[33] W. A. Kirk and B. Panyanak, "A concept of convergence in geodesic spaces," Nonlinear Analysis. Theory, Methods \& Applications. An International Multidisciplinary Journal, vol. 68, no. 12, pp. 3689-3696, 2008.

[34] A. R. Khan, H. Fukhar-ud-din, and M. Khan, "An implicit algorithm for two finite families of nonexpansive maps in hyperbolic spaces," Fixed Point Theory and Applications, vol. 54, no. 12, 2012.

[35] J. J. Nieto and R. Rodriguez-López, "Contractive mapping theorems in partially ordered sets and applications to ordinary differential equations," Order, vol. 22, no. 3, pp. 223-239, 2005. 


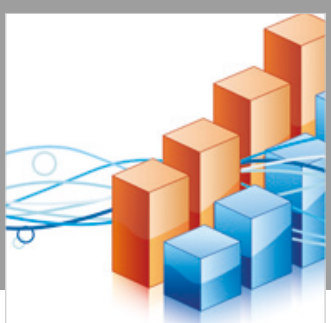

Advances in

Operations Research

\section{-n-m}
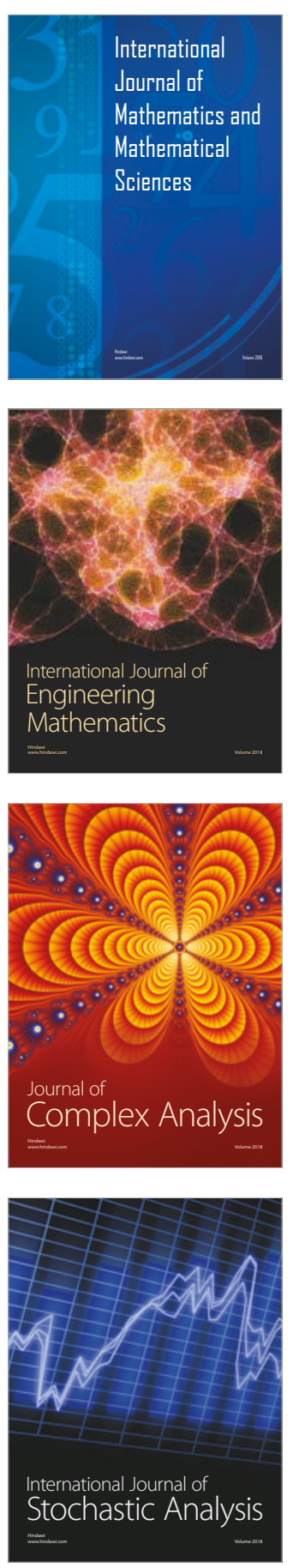
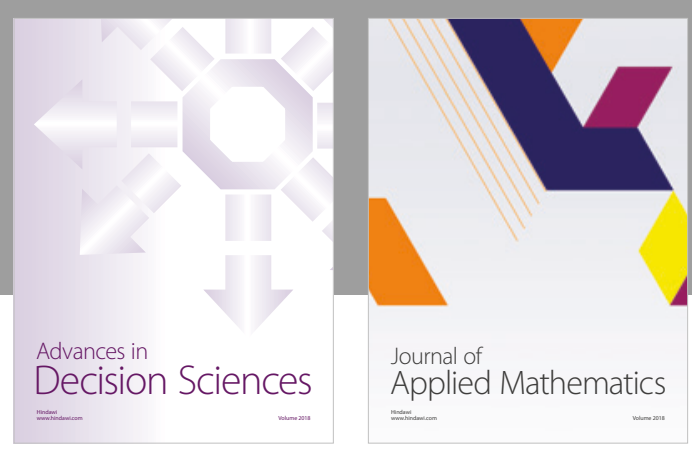

Journal of

Applied Mathematics
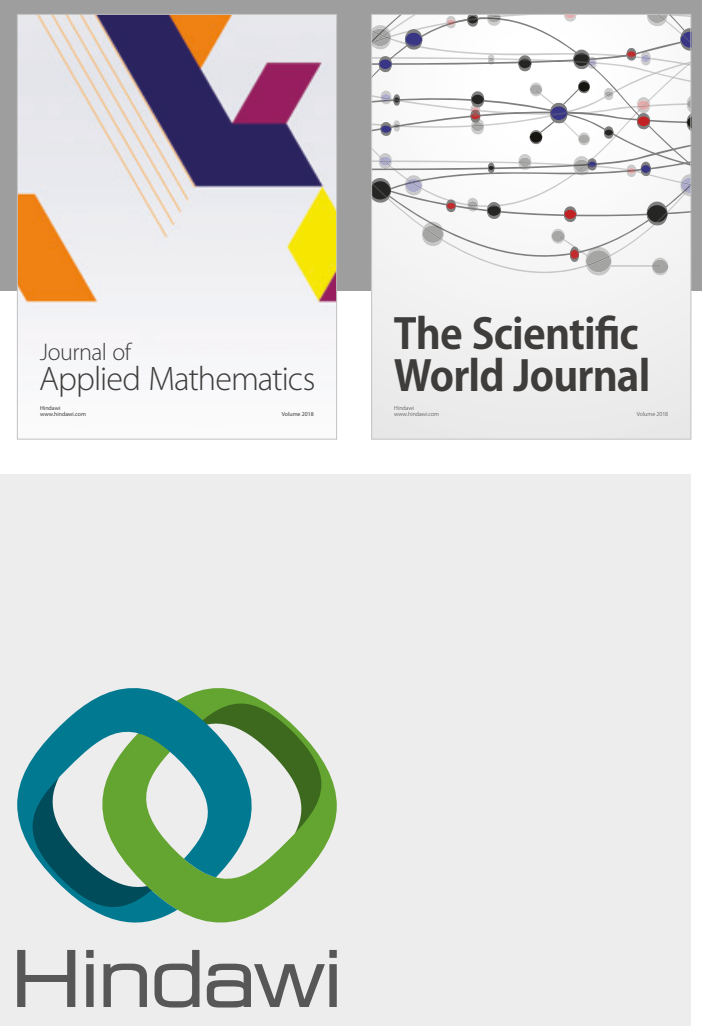

Submit your manuscripts at

www.hindawi.com

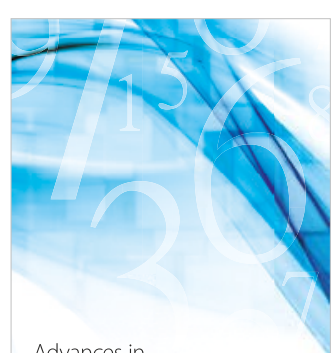

Advances in
Numerical Analysis
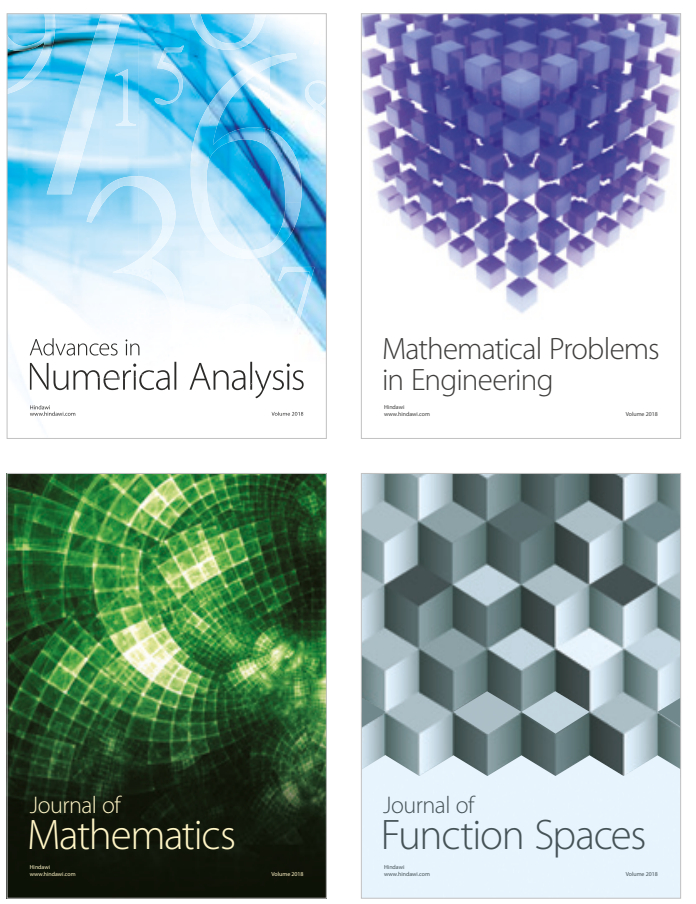

Mathematical Problems in Engineering

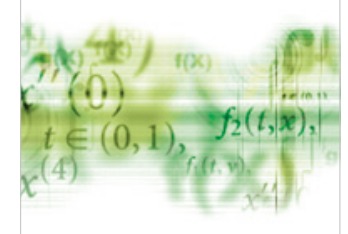

International Journal of

Differential Equations

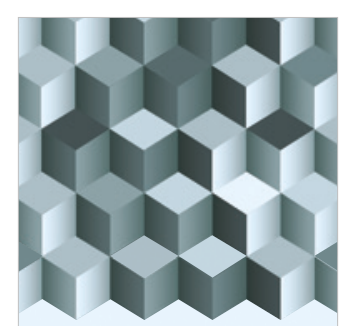

Journal of

Function Spaces

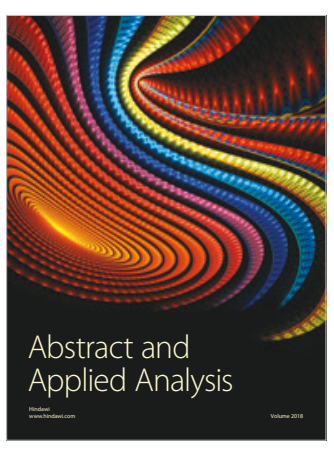

The Scientific

World Journal

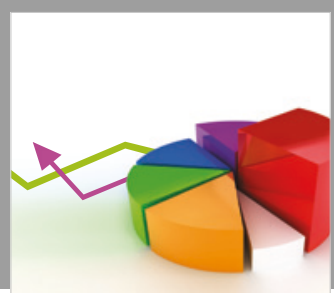

Journal of

Probability and Statistics
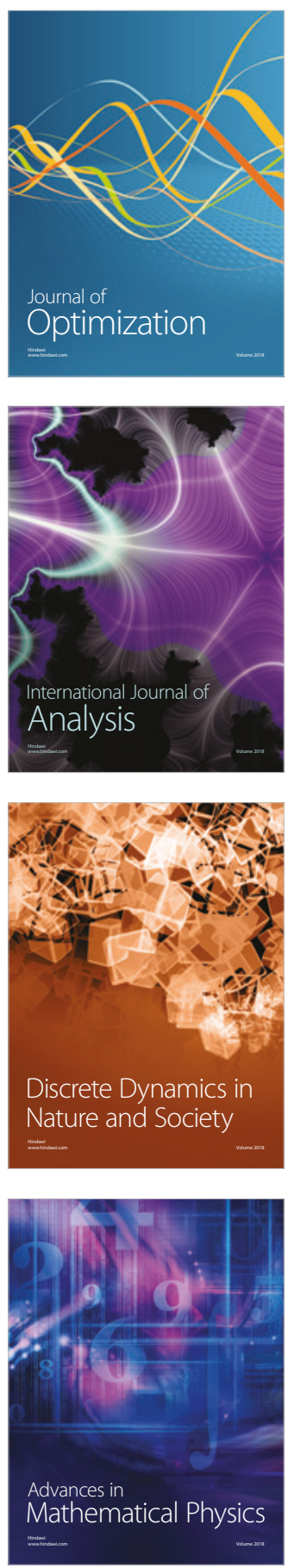